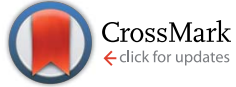

Cite this: RSC Adv., 2017, 7, 17640

Received 22nd January 2017 Accepted 8th March 2017

DOI: $10.1039 / c 7 r a 00958 e$

rsc.li/rsc-advances

\section{Epitaxial crystallization of precisely bromine- substituted polyethylene induced by carbon nanotubes and graphene $\uparrow$}

\author{
Weijun Miao, ${ }^{a}$ Bingjie Wang, ${ }^{b}$ Yiguo Li, ${ }^{c}$ Wenge Zheng, ${ }^{d}$ Hongbing Chen, ${ }^{a}$ Li Zhang ${ }^{\star a}$ \\ and Zongbao Wang*a
}

Precisely substituted polyethylenes have well-defined primary structures and aggregation architecture. Herein, precisely bromine-substituted polyethylene ( $\mathrm{PE} 21 \mathrm{Br}$ ) was chosen as an ideal model to investigate the substituent impact on epitaxial crystallization upon one-dimensional carbon nanotubes (CNT) and two-dimensional reduced graphene oxide (RGO) via solution crystallization. The abilities of different dimensional nanofillers to induce ordered chain packing structures were compared. Transmission electron microscopy (TEM) images showed that kebab-like and rod-like nanofiller-induced crystals were separately observed on the surfaces of CNT and graphene, and selected area electron diffraction (SAED) pattern revealed that the $c$-axis of the polymer chain was parallel to the surface of RGO. Fast-scan differential scanning calorimetry (Flash DSC) revealed that the melting points of the crystals grown on CNT and graphene were increased by 19 and $99{ }^{\circ} \mathrm{C}$, respectively. More importantly, X-ray diffraction (XRD) suggested that CNT and RGO induced the transition of the crystal structure of PE21Br from the triclinic to orthorhombic form, but with different orderness. More ordered lattice structures and higher melting temperatures of $\mathrm{PE} 21 \mathrm{Br} / \mathrm{RGO}$ nanocomposites are ascribed to the perfect lattice matching between PE21Br and RGO. This study not only provides a method for fabricating bromine-functionalized polyolefin nanocomposites, but is also anticipated to open up a new opportunity for improving the service temperature of substituted polyethylene by means of epitaxial crystallization.

\section{Introduction}

Surface-induced polymer crystallization has attracted significant attention from both fundamental and applied aspects of research in the past few years and provides an efficient way to fabricate special structures with desired properties and/or functionality. ${ }^{1-7}$ The occurrence of the epitaxial crystallization of polymers on foreign surfaces is based on certain crystallographic matches, according to many investigation results: i.e., the mismatching of the contact crystallographic planes between substrate and polymer should not exceed $15 \% .^{\mathbf{1 , 4 , 7 - 9}}$ Therefore, one-dimensional or two-dimensional crystallographic matches

${ }^{a}$ Ningbo Key Laboratory of Specialty Polymers, Faculty of Materials Science and Chemical Engineering, Ningbo University, Ningbo 315211, China. E-mail: zhangli2@nbu.edu.cn; wangzongbao@nbu.edu.cn

${ }^{b}$ State Key Laboratory of Molecular Engineering of Polymers, Fudan University, Shanghai 200428, China

${ }^{c}$ Collaborative Innovation Center for Petrochemical New Materials, School of Chemistry and Chemical Engineering, Anqing Normal University, Anqing 246011, China

${ }^{d}$ Ningbo Key Laboratory of Polymer Materials, Ningbo Institute of Material Technology and Engineering, Chinese Academy of Sciences, Ningbo 315201, China

$\dagger$ Electronic supplementary information (ESI) available. See DOI: 10.1039/c7ra00958e generate special interactions between the polymer chains and substrate upon contacting the interface, which can alter the crystal structure and morphology of the polymer, as well as the crystallization kinetics.

One-dimensional carbon nanotubes (CNT) and twodimensional graphene have attracted significant interest in both basic and applied research over the past ten years due to their unique properties. ${ }^{10-13}$ High surface area is favorable for both of these nanofillers to induce polymer crystallization. ${ }^{\mathbf{1 4 - 2 1}} \mathrm{It}$ has been well documented that the topological structure of the substrate has a great impact on the polymer crystallization behavior. ${ }^{22-27}$ For one-dimensional CNT, the mechanism of CNT inducing polymers to form disk-like crystal lamellae has been described as soft epitaxy. ${ }^{28-30}$ However, for two-dimensional graphene, lattice matching dominates the surface-induced polymer epitaxial crystallization. ${ }^{\mathbf{1 7}, 31,32}$ Moreover, the morphology and chain packing structure of crystals formed on nanofillers intensively depend on the crystallization mechanism. For instance, CNT can induce the molecular chain of PLLA to form disk-like lamellae and give rise to an ordered conformation during the early period of the overall crystallization. ${ }^{16,33}$ The crystalline lattice matching of PE and graphene generated thicker edge-on lamellae and a stable monoclinic form..$^{32,34-36}$ It was also reported that CNT and graphene possess the varied ability to 
induce polymer crystallization. Li et $a .^{16}$ found that both onedimensional CNTs and two-dimensional graphene nanosheets (GNSs) can serve as nucleating agents to accelerate the crystallization kinetics of PLLA, and the nucleation ability of CNTs is stronger than that of GNSs. However, the opposite results have also been reported. Simulation studies again exhibited that graphene has much stronger interactions with polymers and thus displays more important influence on the structures and properties of polymers than CNT as well as other nanoparticles. ${ }^{37,38}$

In our previous studies, ${ }^{39,40}$ the precise acyclic diene metathesis polymerization (ADMET) polyethylenes with halogen atoms ( $\mathrm{F}$ and $\mathrm{Cl}$ ) placed on each 21st backbone carbon (PE21F and $\mathrm{PE} 21 \mathrm{Cl}$, respectively) were chosen to investigate the effects of structural change upon the epitaxial crystallization of the substituted-polymers. The results showed that CNT had almost no effect on the crystal structure of both PE21F and PE21Cl, whereas reduced graphene oxide (RGO) induced the structural transformation of $\mathrm{PE} 21 \mathrm{Cl}$ from the triclinic to orthorhombic form and generated extraordinarily high melting temperatures. ${ }^{39,40}$ The two distinctively different crystal structures resulting from variant surfaces not only suggest that precisely substituted polyethylenes are an ideal model to study the influence of substituents on epitaxial crystallization, but also indicate the different inducing abilities of CNT and graphene.

The influence of substituents on the chain packing of $\mathrm{PE}$ crystals is remarkable and becomes more and more severe with the increasing substituent volume. Taking precision halogensubstituted polyethylene as an example, the orderness of the lattice structure of $\mathrm{PE} 21 \mathrm{Br}$ (the precision ADMET polyethylene with bromine placed on each 21st backbone carbon) is much worse compared to those of PE21F and PE21Cl, which hence results in lower melting temperatures. ${ }^{41}$ In this study, PE21Br was chosen as a model to further investigate the substituent impact on the epitaxial crystallization of a polymer. On the other hand, because of severe interference on the orderness of continuous methylene sequences, a bulkier substituent would be helpful in investigating the capacity of nanofillers with different topological structures to induce substituted polymers to crystallize and generate ordered chain packing structures.
The lamellar morphology of polyethylene periodically substituted by bromine, formed on CNT and RGO, is clearly revealed by transmission electron microscopy (TEM); the crystal structures of the nanocomposites have been described on the basis of X-ray diffraction (XRD), and the thermal behaviors were characterized by fast-scan differential scanning calorimetry (Flash DSC 1). We have also discussed the discrepancy between crystal structures and melting temperatures for both nanocomposites. The results obtained are expected to establish a better understanding of the relationship between the structures and properties of the polymer composites enhanced by these two differently structured nanoparticles.

\section{Experimental}

\subsection{Materials}

Purified HiPco single-walled CNTs (SWCNTs, with an average diameter of $6 \mathrm{~nm}$ ) purchased from Times Nanotechnologies Inc. were used as received. RGO was prepared by thermal exfoliation and reduction of graphene oxide (GO). ${ }^{42}$ The precision ADMET polyethylene with $\mathrm{Br}$ atoms placed on each 21st backbone carbon was studied and labeled as PE21Br, where the number corresponds to the precise location of the side group in the PE backbone. The synthesis of PE21Br required the preparation of the $\alpha-\omega$ diene monomer, followed by ADMET polymerization $^{41}$ and subsequent exhaustive hydrogenation, as shown in Scheme 1. The chemical structure was characterized by ${ }^{1} \mathrm{H}$ NMR (see the ESI Fig. S1†). The molecular weight was determined by GPC using an Agilent PL-GPC 220 instrument with HPLC grade chloroform as the mobile phase at the flow rate of $1.0 \mathrm{~mL} \mathrm{~min}^{-1}$ and calibration with polystyrene standards $\left(M_{\mathrm{n}}=10893 \mathrm{~g} \mathrm{~mol}^{-1}, M_{\mathrm{w}} / M_{\mathrm{n}}=1.79\right)$.

\subsection{Sample preparation}

The fabrication process for $\mathrm{PE} 21 \mathrm{Br} /$ nanofiller composites is illustrated in Scheme 2. The nanofiller/ $p$-xylene mixed solution with the nanofiller mass concentration of $0.1 \mathrm{wt} \%$ was ultrasonicated for $2-3 \mathrm{~h}$ at $45{ }^{\circ} \mathrm{C}$ to form the nanofiller- $p$-xylene
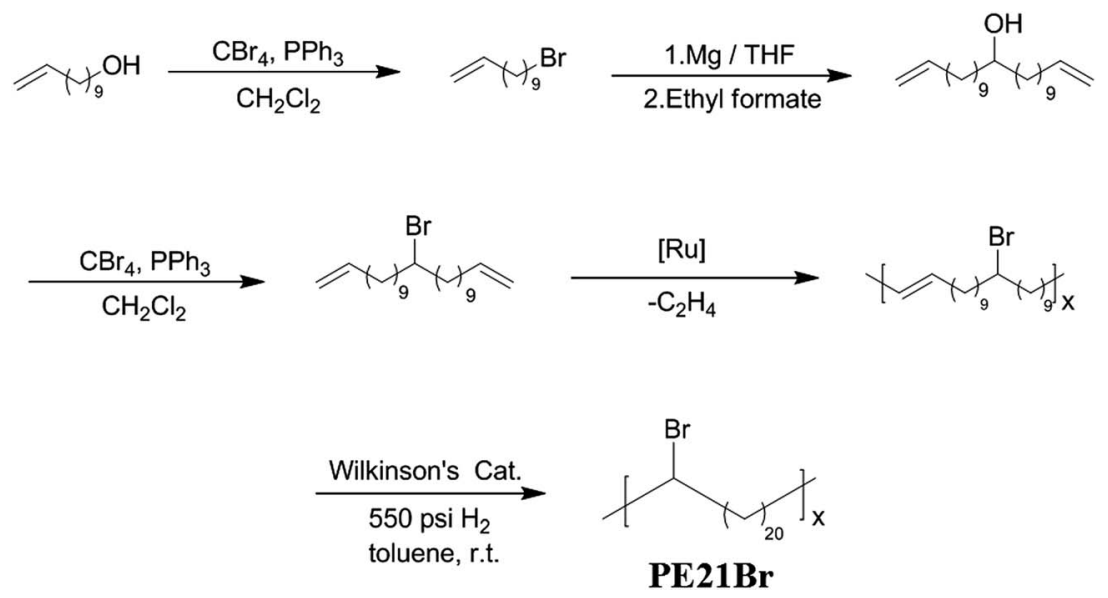

Scheme 1 Monomer and polymer synthesis process. 


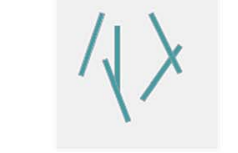

0.1 wt\% nanofillers/ p-xylene dispersion

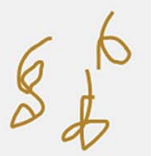

$0.1 \mathrm{wt} \%$ PE21Br/ p-xylene solution
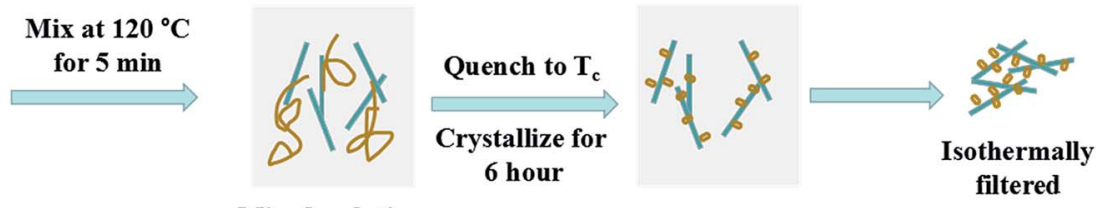

Mixed solution

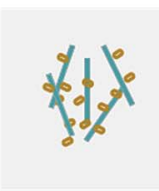

Washed by ethanol for 3 times

Scheme 2 Fabrication process of PE21Br/nanofiller composites.

suspension. The PE21Br/p-xylene mixed solution with PE21Br mass concentration of $0.1 \mathrm{wt} \%$ was prepared by dissolving PE21Br in $p$-xylene at $120^{\circ} \mathrm{C}$ for $2 \mathrm{~h}$. Then, $10 \mathrm{~g}$ of nanofiller $/ p$ xylene solution was mixed with $10 \mathrm{~g}$ of $\mathrm{PE} 21 \mathrm{Br} / p$-xylene solution at $120{ }^{\circ} \mathrm{C}$ for $5 \mathrm{~min}$. The mixture was then quenched at the preset crystallization temperature $T_{\mathrm{c}}$. To avoid SWCNTs from agglomerating and forming small bundles in the solvent, the mixed solution was stirred at $1200 \mathrm{rpm}$. The sample was isothermally filtered after crystallization for $6 \mathrm{~h}$ and after carefully washing 3 times with ethanol, the nanocomposites were dried at $40{ }^{\circ} \mathrm{C}$ in vacuum for $36-48 \mathrm{~h}$.

The method used by Xu et al. ${ }^{43-46}$ for preparing PE nanocomposites, using supercritical $\mathrm{CO}_{2}\left(\mathrm{SC} \mathrm{CO}_{2}\right)$, was employed. The mixture of nanofiller/ $p$-xylene solution and $\mathrm{PE} 21 \mathrm{Br} / p$-xylene solution was prepared by the same procedure as abovementioned. The mixture was then quickly transferred into a stainless steel autoclave at the preset crystallization temperature $T_{\mathrm{c}}$. SC $\mathrm{CO}_{2}$ was then charged in the autoclave to the desired pressure within a short time. After maintaining the supercritical fluid condition for $3 \mathrm{~h}$, the system was slowly depressurized and the sample was obtained and labelled.

\subsection{Characterization}

Transmission electron microscopy (TEM) and selected area electron diffraction (SAED) experiments were conducted using a JEOL JEM2100 transmission electron microscope with an accelerating voltage of $200 \mathrm{kV}$. Nanocomposite suspensions were obtained on a carbon-coated TEM grid. The fast-scan differential scanning calorimetry experiments were performed via the commercialized FSC (Flash DSC1, Mettler-Toledo, Switzerland). Before any analysis, the empty chip-sensor experienced the standard procedure for conditioning and calibration. To achieve a sufficiently good contact between the sample and the chip-sensor, a small trace of silicon oil was dropped onto both cells before the sample and the reference were transferred. The samples were heated from 30 to $240{ }^{\circ} \mathrm{C}$ at the scanning rate of $1000 \mathrm{~K} \mathrm{~s}^{-1}$ and nitrogen gas was used as the protective

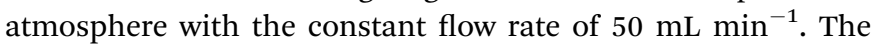
STARe software (Version 10.0) was employed to perform the data treatment. The X-ray diffraction (XRD) patterns were obtained using a Bruker D8 diffractometer, with Ni-filtered $\mathrm{Cu} \mathrm{K} \alpha$ radiation at $40 \mathrm{kV}$ and $30 \mathrm{~mA}$ at room temperature at the angles ranging from 5 to $80^{\circ}$ at the rate of $3.5^{\circ} \mathrm{min}^{-1}$.

\section{Results and discussion}

\subsection{Morphologies of the PE21Br/nanofiller composites}

3.1.1. Morphologies of the PE21Br/CNT kebab-like crystals. Fig. 1 shows the PE21Br shish-kebab crystals in which PE21Br lamellae (as the kebab) are periodically decorated on SWCNTs (as shish) at all the selected experimental temperatures. Average sizes of PE21Br lamellae formed on SWCNTs are presented in Table 1 based on the measurement of 200 lamellae. The average diameters of the PE21Br kebab crystals are about $17.2 \pm 1.1$, $23.2 \pm 1.2$, and $18.4 \pm 0.9 \mathrm{~nm}$ for crystallization at 40,50 , and $60{ }^{\circ} \mathrm{C}$, respectively. It is evident that the average diameter of the PE21Br kebab crystals first increases, then decreases with the increase in crystallization temperature, and the kebab crystal with the largest diameter forms at $50{ }^{\circ} \mathrm{C}$. This behavior is consistent with that of PE21F and PE21Cl crystals reported in

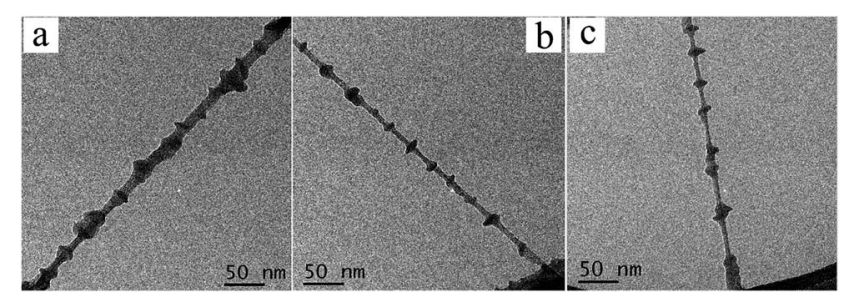

Fig. 1 TEM images of PE21Br/SWCNT nanocomposites produced in $p$-xylene at different temperatures for $6 \mathrm{~h}$. (a) $40{ }^{\circ} \mathrm{C}$, (b) $50{ }^{\circ} \mathrm{C}$, and (c) $60^{\circ} \mathrm{C}$ (both PE21Br and SWCNT concentrations are $0.05 \mathrm{wt} \%$ ). 
our previous studies, ${ }^{39,40}$ which can be attributed to the competition of nucleation and crystal growth on the CNT. Unlike the changes in the diameters, the kebab interval monotonically increases with the increase in the crystallization temperature (Table 1) because the crystal nucleus becomes less and less stable with the decrease in the degree of undercooling. It is well known that lamellae thickness, corresponding to the crystallization of the ethylene sequence, is strongly dependent on the crystallization temperature. Consequently, the thickness of kebab crystals increases with the increasing crystallization temperature: from $6.0 \pm 0.6 \mathrm{~nm}$ at $40{ }^{\circ} \mathrm{C}$ to $6.8 \pm 0.5 \mathrm{~nm}$ at $60{ }^{\circ} \mathrm{C}$ (Table 1). From the data analysis shown in Table 1 , one can draw the conclusion that the crystallization temperature has great influence on the size and periodicity of the shish-kebab crystals and the most suitable crystallization temperature for $\mathrm{PE} 21 \mathrm{Br} / \mathrm{SWCNT}$ in $p$-xylene is $50^{\circ} \mathrm{C}$. In contrast to the previous study, it was found that the diameter of the PE21Br kebab is much smaller than that of HDPE (50-80 nm) ${ }^{30}$ and PE21F (54$65 \mathrm{~nm}$ ) (van der Waals radius of $\mathrm{F}$ is $1.52 \AA)^{39}$ and also smaller than that of PE21Cl $(26.2 \pm 1.0 \mathrm{~nm})$ (the van der Waals radius of $\mathrm{Cl}(1.75 \AA)$ is smaller than that of $\operatorname{Br}(1.85 \AA)) .{ }^{40}$ The diameter of the kebab decreases with the increasing volume of the substituent, indicating that the substituent, as a defect of the chain, greatly influences the lateral growth of the crystal lamellae. A larger substituent also causes greater disturbance of the crystallization of $\mathrm{PE}$, which is evidenced by the fact that the thickness of PE21Br kebabs is smaller than that of PE21F formed at the same undercooling degree $\left(10{ }^{\circ} \mathrm{C}\right) .{ }^{39}$ However, the thickness of kebabs does not consistently decrease, as anticipated, with the increasing volume of the substituents. Unexpectedly, the thickness of PE21Br kebabs $(6.8 \pm 0.5 \mathrm{~nm})$ is almost the same as that of PE21Cl $(6.4 \pm 0.5 \mathrm{~nm}) .{ }^{40}$ It suggests that PE21Br and PE21Cl crystals formed on CNT have analogous crystallization sequence length.

3.1.2. Morphologies of the PE21Br/RGO rod-like crystals. RGO has a two-dimensional flat area, unlike one-dimensional CNT, which is helpful for strict epitaxial crystallization. Three different crystallization temperatures $\left(50,60\right.$, and $\left.70{ }^{\circ} \mathrm{C}\right)$, same as for PE21Br/SWCNT nanocomposites, were chosen to prepare PE21Br/RGO nanocomposites. The crystal morphologies (Fig. 2) show that RGO is covered with rod-like crystals. The rod-like crystals prefer to be arranged in three directions that are about $60^{\circ}$ apart from each other, which indicates the strict epitaxial crystallization between PE21Br and RGO. Note that the regularity of $\mathrm{PE} 21 \mathrm{Br}$ crystals formed on RGO is much poorer as compared to that of the PE21F and PE21Cl crystals. ${ }^{39,40}$ The average sizes of PE21Br crystals (listed in Table 2) are about $15 \pm$ $1.2,54 \pm 2.3$, and $43 \pm 1.5 \mathrm{~nm}$ at 50,60 , and $70{ }^{\circ} \mathrm{C}$, respectively,

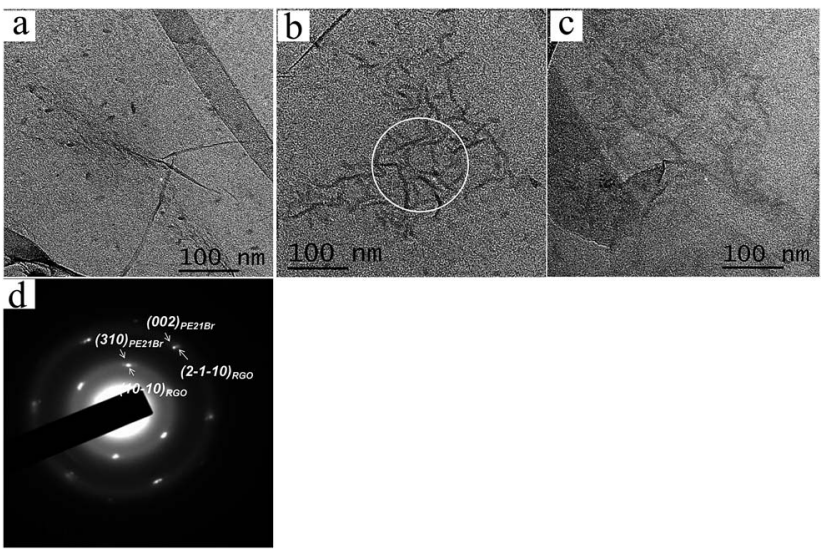

Fig. 2 TEM images of PE21Br/RGO nanocomposites produced in $p$ xylene at different temperatures for $6 \mathrm{~h}$. (a) $50{ }^{\circ} \mathrm{C}$, (b) $60^{\circ} \mathrm{C}$, and (c) $70{ }^{\circ} \mathrm{C}$. (d) The selected-area electron diffraction (SAED) pattern of the circled area of (b) (both PE21Br and RGO concentrations are $0.05 \mathrm{wt} \%$ ).

Table 2 Average size of PE21Br lamellae formed on RGO based on the TEM images of 200 lamellae

\begin{tabular}{llll}
\hline $\begin{array}{l}\text { Sample } \\
\text { (crystallization } \\
\text { temperature) }\end{array}$ & $\begin{array}{l}\text { Size of } \\
\text { lamellae } \\
(\mathrm{nm})\end{array}$ & $\begin{array}{l}\text { Thickness of } \\
\text { lamellae } \\
(\mathrm{nm})\end{array}$ & $\begin{array}{l}\text { Density } \\
(\text { number/ } \\
\left.0.01 \mu \mathrm{m}^{2}\right)\end{array}$ \\
\hline $\mathrm{PE} 21 \mathrm{Br} / \mathrm{RGO}\left(50^{\circ} \mathrm{C}\right)$ & $15 \pm 1.2$ & $5.0 \pm 0.6$ & 15 \\
$\mathrm{PE} 21 \mathrm{Br} / \mathrm{RGO}\left(60^{\circ} \mathrm{C}\right)$ & $53 \pm 2.3$ & $6.7 \pm 0.4$ & 37 \\
$\mathrm{PE} 21 \mathrm{Br} / \mathrm{RGO}\left(70^{\circ} \mathrm{C}\right)$ & $42 \pm 1.5$ & $6.9 \pm 0.4$ & 29
\end{tabular}

based on the measurement of 200 lamellae. Note that $\mathrm{PE} 21 \mathrm{Br} /$ RGO nanocomposites cannot be produced at crystallization temperatures below $50{ }^{\circ} \mathrm{C}$. One can see that only discrete nuclei and quite small rod-like crystals can be observed on the surface of RGO nanosheets at $50{ }^{\circ} \mathrm{C}$. Once the crystallization temperature increases to $60^{\circ} \mathrm{C}$, small nuclei and crystals of PE21Br grow into largest lamellae with an average size of $53 \pm 2.3 \mathrm{~nm}$. This effect may be attributed to the lattice matching playing the dominant role in epitaxial crystallization of the polymer on the two-dimensional graphite layer, and $\mathrm{PE} 21 \mathrm{Br}$ chains require more time or much higher crystallization temperature to adjust their conformations to the surface of RGO. Even when the crystallization temperature was successively increased to $70{ }^{\circ} \mathrm{C}$, about $6{ }^{\circ} \mathrm{C}$ above the melting temperature of $\mathrm{PE} 21 \mathrm{Br}$, rod-like crystals were again formed although the average value of the size of lamellae decreased to $42 \pm 1.5 \mathrm{~nm}$. This phenomenon is similar to the crystallization behavior of PE21Br on SWCNT. The density (number/0.01 $\mu^{2}$ ) of lamellae decreased from 37 at

Table 1 Average size of PE21Br lamellae formed on SWCNT, based on the TEM images of 200 lamellae

\begin{tabular}{|c|c|c|c|}
\hline $\begin{array}{l}\text { Sample (crystallization } \\
\text { temperature) }\end{array}$ & $\begin{array}{l}\text { Diameter of the } \\
\text { kebab-like crystals }(\mathrm{nm})\end{array}$ & $\begin{array}{l}\text { Thickness of the } \\
\text { kebab-like crystals (nm) }\end{array}$ & $\begin{array}{l}\text { Interval of kebab-like } \\
\text { crystals (nm) }\end{array}$ \\
\hline $\mathrm{PE} 21 \mathrm{Br} / \mathrm{SWCNT}\left(40^{\circ} \mathrm{C}\right)$ & $17.2 \pm 1.1$ & $6.0 \pm 0.6$ & $16.3 \pm 1.2$ \\
\hline $\mathrm{PE} 21 \mathrm{Br} / \mathrm{SWCNT}\left(50^{\circ} \mathrm{C}\right)$ & $23.2 \pm 1.2$ & $6.6 \pm 0.5$ & $26.7 \pm 1.4$ \\
\hline $\mathrm{PE} 21 \mathrm{Br} / \mathrm{SWCNT}\left(60^{\circ} \mathrm{C}\right)$ & $18.4 \pm 0.9$ & $6.8 \pm 0.5$ & $34.5 \pm 1.4$ \\
\hline
\end{tabular}


$60{ }^{\circ} \mathrm{C}$ to 29 at $70{ }^{\circ} \mathrm{C}$, as given in Table 2 . When the isothermal crystallization temperature increases, the number of rod-like crystal lamellae decreases for the less stable crystal nucleus to exist at lower undercooling degree. The average size and density of PE21Br lamellae formed on RGO are also much smaller than those of PE21F and PE21Cl lamellae, ${ }^{39,40}$ which further indicates that the influence of substituents on crystal growth becomes greater with the increase in substituent volume. We can also see from Table 2 that the thickness of the rod-like crystals increases with the increasing crystallization temperature. It is also suggested that the isothermal crystallization temperature plays a decisive role in the thickness and density of lamellae formed on RGO. By comparing Tables 1 and 2, we found that the average thickness of rod-like crystals of PE21Br formed on RGO is almost the same as that of the kebab crystals formed on SWCNT under the same crystallization conditions, again suggesting that the thickness of PE21Br crystals on both CNT and RGO is determined by the crystallization temperature. However, the uniformity of the thickness of rod-like crystals induced by RGO is better than that of kebab crystals, which may be due to the fact that the two-dimensional RGO is helpful for strict epitaxial crystallization. Comparing $\mathrm{PE} 21 \mathrm{Br}$ with $\mathrm{PE} 21 \mathrm{~F}^{39}$ and HDPE ${ }^{17}$ the maximal thickness and size of PE21Br lamellae formed on RGO is about $6.9 \mathrm{~nm}$ and $53 \mathrm{~nm}$, which is smaller than $8.8 \mathrm{~nm}$ and $73 \mathrm{~nm}$ for PE21F and $13 \mathrm{~nm}$ and $100 \mathrm{~nm}$ for HDPE. It is also attributed to the influence of $\mathrm{Br}$ substituent. The thickness of PE21Br lamellae formed on RGO $(6.9 \pm 0.4$ $\mathrm{nm})$ is also the same as that of PE21Cl $(6.5 \pm 0.4 \mathrm{~nm}) .{ }^{40}$

Fig. 2d shows the selected area electron diffraction (SAED) pattern of the circled area shown in Fig. 2b. Orthorhombic reflection spots of $\mathrm{PE} 21 \mathrm{Br}$ can be observed, and the innermost diffractions of PE21Br are overlapped with RGO $\left(\begin{array}{llll}1 & 0 & -1 & 0\end{array}\right)$ diffractions, and the next six symmetric weak $\mathrm{PE} 21 \mathrm{Br}$ reflection spots are close to RGO $(2-1-10)$ reflections. The diffraction patterns of PE21Br crystals formed on the surfaces of RGO are similar to those of polyethylene orthorhombic crystals formed on the surfaces of graphite, ${ }^{31}$ highly oriented pyrolytic graphite (HOPG),,$^{32}$ and RGO. ${ }^{17}$ They are also identical to those of PE21F ${ }^{39}$ and $\mathrm{PE} 21 \mathrm{Cl}^{40}$ orthorhombic crystals formed on the surfaces of RGO: the (002) and (310) reflection spots of the orthorhombic

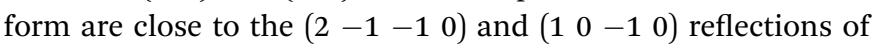
RGO, respectively. According to the abovementioned analysis, we can deduce that $\mathrm{PE} 21 \mathrm{Br}$ rod-like crystals formed on the surfaces of RGO are the orthorhombic form, and the PE21Br chains in the edge-on crystal are parallel to the basal plane of the RGO sheets.

3.1.3. PE21Br/nanofiller composites prepared with the assistance of supercritical $\mathbf{C O}_{2}$. Supercritical $\mathrm{CO}_{2}\left(\mathrm{SC} \mathrm{CO}_{2}\right)$ could facilitate the crystallization of polymers because of the antisolvent effect, ${ }^{43}$ which was used herein to further study the influence of crystallization conditions on the epitaxial crystallization of PE21Br. PE21Br/nanofiller composites were prepared in $p$-xylene at $50{ }^{\circ} \mathrm{C}$ for $\mathrm{PE} 21 \mathrm{Br} / \mathrm{SWCNT}$ nanocomposites and $60{ }^{\circ} \mathrm{C}$ for $\mathrm{PE} 21 \mathrm{Br} / \mathrm{RGO}$ nanocomposites, with the assistance of $\mathrm{SC} \mathrm{CO}_{2}$; the experimental pressure of $\mathrm{SC} \mathrm{CO}_{2}$ was tuned from 10 to 15 to $20 \mathrm{MPa}$. The crystallization morphologies are shown in Fig. 3 and 4. In these cases, the average size of the PE21Br

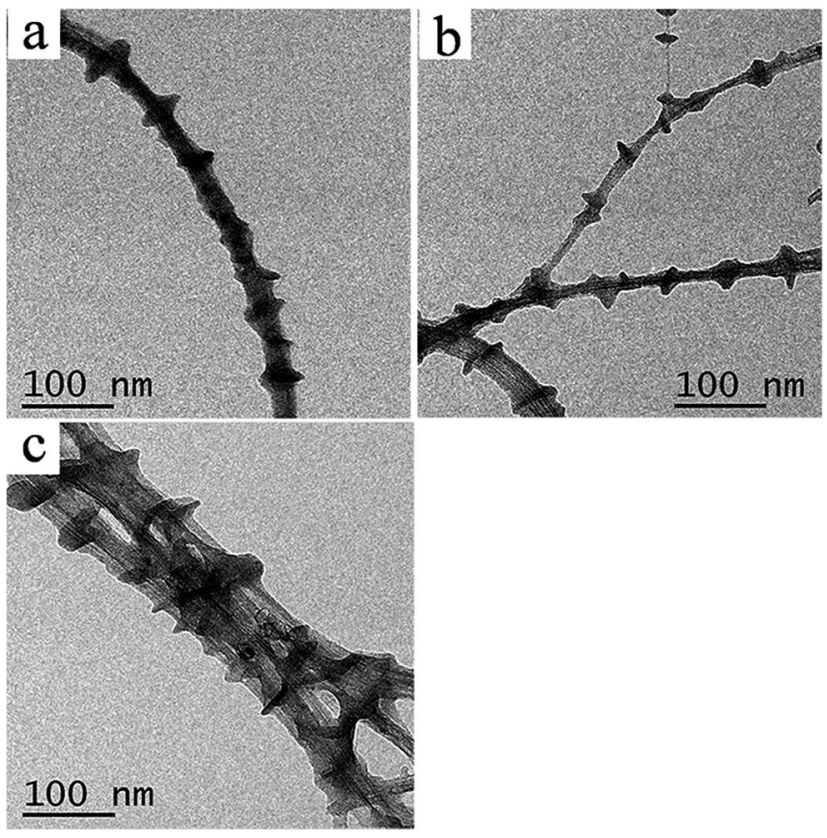

Fig. 3 TEM images of PE21Br/SWCNT nanocomposites produced at different $\mathrm{SC} \mathrm{CO}_{2}$ pressures: (a) $10 \mathrm{MPa}$, (b) $15 \mathrm{MPa}$, and (c) $20 \mathrm{MPa}$ in $p-$ xylene at $50{ }^{\circ} \mathrm{C}$ for $3 \mathrm{~h}$.

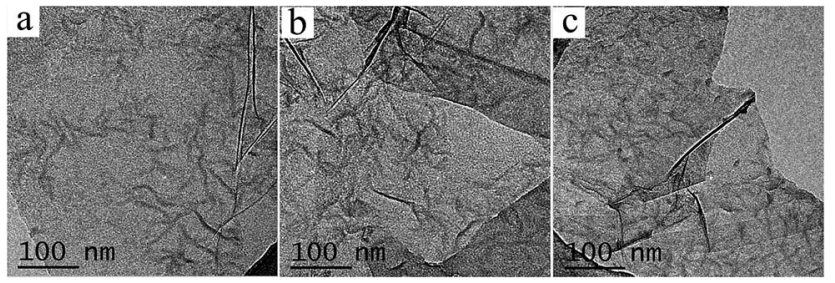

Fig. 4 TEM images of PE21Br/RGO nanocomposites produced at different $\mathrm{SC} \mathrm{CO}_{2}$ pressures: (a) $10 \mathrm{MPa}$, (b) $15 \mathrm{MPa}$, and (c) $20 \mathrm{MPa}$ in $p$ xylene at $60{ }^{\circ} \mathrm{C}$ for $3 \mathrm{~h}$.

lamellar crystals formed on SWCNT and RGO are listed in Tables 3 and 4. SWCNTs are apt to agglomerate and form small bundles at $\mathrm{SC} \mathrm{CO}_{2}$ pressure, and it becomes gradually serious as the $\mathrm{SC} \mathrm{CO}_{2}$ pressures increase. Therefore, the diameter of SWCNT is much thicker than that produced without $\mathrm{SC} \mathrm{CO}_{2}$ (Fig. 1). After $3 \mathrm{~h}$ of isothermal crystallization with the assistance of $\mathrm{SC} \mathrm{CO}_{2}$, the diameter of PE21Br crystals formed on SWCNT at $50{ }^{\circ} \mathrm{C}$ and $10 \mathrm{MPa}$ is $25.8 \pm 1.3 \mathrm{~nm}$, larger than that of crystals formed after $6 \mathrm{~h}$ of isothermal solution crystallization $(23.2 \pm 1.2 \mathrm{~nm}$, Table 1$)$. As the $\mathrm{SC} \mathrm{CO}_{2}$ pressure increased, the diameter of PE21Br formed on SWCNT at $15 \mathrm{MPa}$ increased to $27.5 \pm 1.3 \mathrm{~nm}$. Similarly, the lamellae size of PE21Br formed on RGO at $10 \mathrm{MPa}$ is $63 \pm 3.0 \mathrm{~nm}$, also larger than that of crystals formed without the assistance of $\mathrm{SC} \mathrm{CO}_{2}$ after $6 \mathrm{~h}$ of isothermal solution crystallization (Table 2). It is suggested that $\mathrm{SC} \mathrm{CO}_{2}$ can accelerate the lateral growth of the lamellae. The diameter of the PE21Br kebab decreases with the increasing pressure of SC $\mathrm{CO}_{2}$, from $27.5 \pm 1.3$ at $15 \mathrm{MPa}$ to $24.5 \pm 1.4 \mathrm{~nm}$ at $20 \mathrm{MPa}$. This rule can also be observed in the PE21Br/RGO system, as indicated in Table 4 . The average sizes of the rod-like crystals of 
Table 3 Average size of PE21Br lamellae formed on SWCNT with the assistance of $\mathrm{SC} \mathrm{CO}_{2}$, based on the TEM images of 200 lamellae

\begin{tabular}{llll}
\hline Sample (pressure) & $\begin{array}{l}\text { Diameter of kebab } \\
\text { crystals (nm) }\end{array}$ & $\begin{array}{l}\text { Thickness of kebab } \\
\text { crystals (nm) }\end{array}$ & $\begin{array}{l}\text { Interval of kebab } \\
\text { crystals (nm) }\end{array}$ \\
\hline PE21Br/SWCNT (10 MPa) & $25.8 \pm 1.3$ & $6.7 \pm 0.8$ & $24.9 \pm 1.4$ \\
PE21Br/SWCNT (15 MPa) & $27.5 \pm 1.3$ & $6.7 \pm 0.7$ & $25.3 \pm 1.2$ \\
PE21Br/SWCNT (20 MPa) & $24.5 \pm 1.4$ & $6.8 \pm 0.8$ & $23.5 \pm 1.3$
\end{tabular}

Table 4 Average size of PE21Br lamellae formed on RGO with the assistance of $\mathrm{SC} \mathrm{CO}_{2}$ based on the TEM images of 200 lamellae

\begin{tabular}{llll}
\hline & $\begin{array}{l}\text { Size of } \\
\text { lamellae }(\mathrm{nm})\end{array}$ & $\begin{array}{l}\text { Thickness of } \\
\text { lamellae }(\mathrm{nm})\end{array}$ & $\begin{array}{l}\text { Density } \\
(\text { number/ } \\
\left.0.01 \mu \mathrm{m}^{2}\right)\end{array}$ \\
\hline PE21Br/RGO (10 MPa) & $63 \pm 3.0$ & $6.7 \pm 0.8$ & 43 \\
PE21Br/RGO (15 MPa) & $70 \pm 3.3$ & $6.9 \pm 0.7$ & 55 \\
PE21Br/RGO (20 MPa) & $48 \pm 2.2$ & $6.9 \pm 0.8$ & 65
\end{tabular}

PE21Br/RGO nanocomposites are about $63 \pm 3.0,70 \pm 3.3$, and $48 \pm 2.2 \mathrm{~nm}$ for 10,15 , and $20 \mathrm{MPa}$, respectively. This phenomenon has also been observed in our previous work ${ }^{39,40}$ and can be attributed to the amount and speed of the PE21Br precipitation being greatly increased at excessively high $\mathrm{CO}_{2}$ pressure. The intervals of kebabs of PE21Br formed on SWCNT became smaller due to the large deposition of the PE21Br chain, from $24.9 \pm 1.4 \mathrm{~nm}$ at $10 \mathrm{MPa}$ and $25.3 \pm 1.2 \mathrm{~nm}$ at $15 \mathrm{MPa}$ to $23.5 \pm 1.3 \mathrm{~nm}$ at $20 \mathrm{MPa}$. Same trend was followed by the density of the lamellae of PE21Br formed on RGO. The thickness of the lamellar crystals produced with the assistance of SC $\mathrm{CO}_{2}$ (Tables 3 and 4 ) is almost consistent with that prepared by traditional solution crystallization. This suggests that $\mathrm{SC} \mathrm{CO}_{2}$ can promote the lateral growth of lamellae on CNT and RGO, but it cannot change the thickness of the crystal lamellae, which is directly related to the crystallization temperature. We can conclude that the optimum $\mathrm{SC} \mathrm{CO}_{2}$ pressure is $15 \mathrm{MPa}$, at which the rod-like lamellae crystals possess the maximum size.

\subsection{Thermal behavior of PE21Br/nanofiller composites}

Fig. 5 shows the melting behaviors of $\mathrm{PE} 21 \mathrm{Br} /$ nanofiller composites measured by fast-scan differential scanning calorimetry (Flash DSC). Flash DSC is sensitive to detecting quite small masses of samples (as low as $10 \mathrm{ng}$ ), and the abnormally fast heating rate can completely suppress the melting recrystallization. ${ }^{47}$ The melting peak temperature of $\mathrm{PE} 21 \mathrm{Br}$ is $77.6^{\circ} \mathrm{C}$, measured by Flash DSC, which is $13{ }^{\circ} \mathrm{C}$ higher than that measured by traditional DSC. The melting temperature shifted to higher temperature compared with traditional DSC because of the superheating effect ${ }^{48,49}$ and thermal lags. ${ }^{47}$

As reflected in Fig. 5a, the melting temperature of the $\mathrm{PE} 21 \mathrm{Br} / \mathrm{SWCNT}$ nanocomposite crystallized at $40{ }^{\circ} \mathrm{C}$ is $71.7^{\circ} \mathrm{C}$, $6{ }^{\circ} \mathrm{C}$ lower than that of PE21Br. It is suggested that the thickness of the lamellae of the $\mathrm{PE} 21 \mathrm{Br} / \mathrm{SWCNT}$ nanocomposite prepared at lower crystallization temperature is much smaller than that of pure PE21Br. The melting temperatures increase with the increasing crystallization temperature, from $94.0^{\circ} \mathrm{C}$ at $50{ }^{\circ} \mathrm{C}$ to $96.8^{\circ} \mathrm{C}$ at $60^{\circ} \mathrm{C}$, which is up to $19^{\circ} \mathrm{C}$ higher than that of $\mathrm{PE} 21 \mathrm{Br}$. The increase rate of melting temperature with the crystallization temperature is higher than that of PE21F/SWCNT nanocomposites, ${ }^{39}$ indicating that higher crystallization temperature is needed for incorporating larger substituents to form longer methylene sequences or adjusting the conformation due to the hindrance of the substituent. Surprisingly, the melting temperature of the $\mathrm{PE} 21 \mathrm{Br} / \mathrm{RGO}$ nanocomposites is $144.5^{\circ} \mathrm{C}$ for crystallization at $60^{\circ} \mathrm{C}$ (Fig. 5b), which is $67^{\circ} \mathrm{C}$ higher than that of PE21Br. Moreover, the melting temperatures of PE21Br/RGO nanocomposites increased to $176.0{ }^{\circ} \mathrm{C}$ at the crystallization
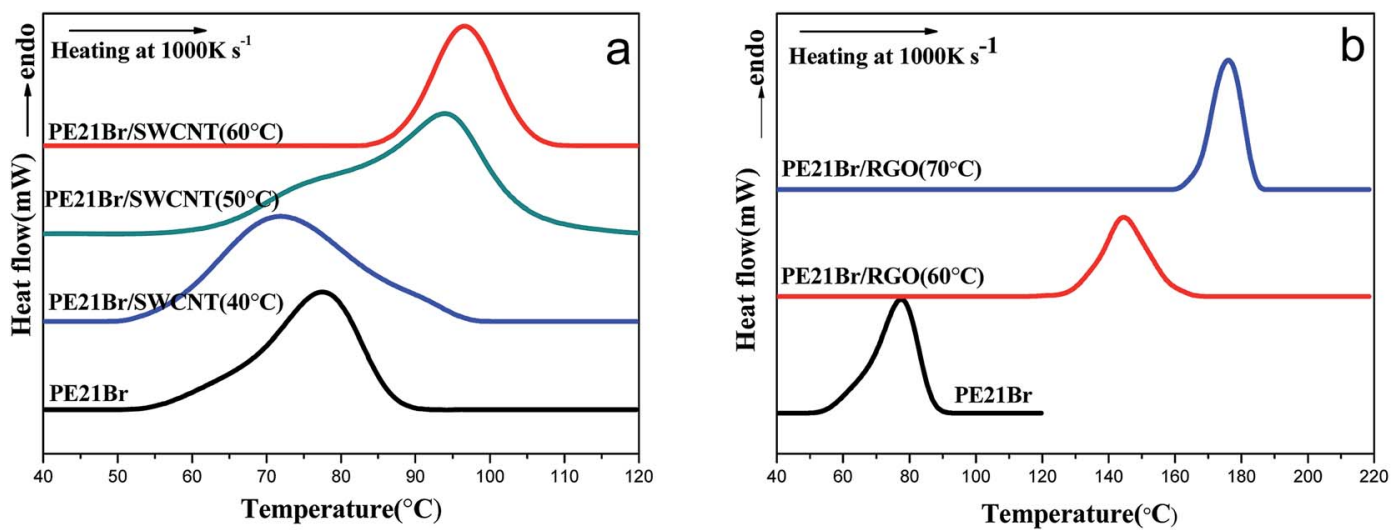

Fig. 5 First heating curves of PE21Br and PE21Br/nanofiller composites at Flash DSC measurement at the heating rate of $1000 \mathrm{~K} \mathrm{~s}{ }^{-1}$. (a) PE21Br/ SWCNT nanocomposites and (b) PE21Br/RGO nanocomposites. 
Table 5 Melting data of PE21Br and PE21Br/nanofiller composites

\begin{tabular}{lccl}
\hline $\begin{array}{l}\text { Sample (crystallization } \\
\text { temperature) }\end{array}$ & $\begin{array}{l}T_{\mathrm{m}}\left({ }^{\circ} \mathrm{C}\right) \\
\text { peak }\end{array}$ & $\begin{array}{l}T_{\mathrm{m}}\left({ }^{\circ} \mathrm{C}\right) \\
\text { onset }\end{array}$ & $\begin{array}{l}\text { Onset-end } \\
\left({ }^{\circ} \mathrm{C}\right)\end{array}$ \\
\hline $\mathrm{PE} 21 \mathrm{Br}$ & 77.6 & 62.3 & 24.8 \\
$\mathrm{PE} 21 \mathrm{Br} / \mathrm{SWCNT}\left(40{ }^{\circ} \mathrm{C}\right)$ & 71.7 & 55.9 & 37.1 \\
$\mathrm{PE} 21 \mathrm{Br} / \mathrm{SWCNT}\left(50^{\circ} \mathrm{C}\right)$ & 94.0 & 73.2 & 32.1 \\
$\mathrm{PE} 21 \mathrm{Br} / \mathrm{SWCNT}\left(60^{\circ} \mathrm{C}\right)$ & 96.8 & 87.9 & 18.7 \\
$\mathrm{PE} 21 \mathrm{Br} / \mathrm{RGO}\left(60{ }^{\circ} \mathrm{C}\right)$ & 144.5 & 131.0 & 28.9 \\
$\mathrm{PE} 21 \mathrm{Br} / \mathrm{RGO}\left(70{ }^{\circ} \mathrm{C}\right)$ & 176.0 & 166.3 & 18.1 \\
& & &
\end{tabular}

temperature of $70{ }^{\circ} \mathrm{C}$. PE21Br/RGO crystals and PE21Br/SWCNT crystals have similar thickness as abovementioned, which convinced us that the remarkably higher melting temperatures are not caused by the thicker lamellae formed on RGO: i.e., there should be another factor inducing this particular behavior. It is known that PE21Br has a lower melting temperature compared to $\mathrm{PE} 21 \mathrm{~F}$ because the bulkier $\mathrm{Br}$ substituent disturbs the length of the continuous methylene sequences. ${ }^{51}$ However, PE21Br/SWCNT nanocomposites prepared at higher crystallization temperatures and $\mathrm{PE} 21 \mathrm{Br} / \mathrm{RGO}$ nanocomposites possess particularly higher melting temperatures. These results suggest that SWCNT and RGO may induce PE21Br to form crystals with different structures, which can be indicated by abovementioned SAED and has been illustrated by XRD in the following section. Furthermore, the melting range of polymers can also be a reflection of the uniformity of lamellae thickness. It is evident that the melting ranges (span of onset-end shown in Table 5) of PE21Br/RGO composites are smaller than those of $\mathrm{PE} 21 \mathrm{Br} / \mathrm{SWCNT}$ composites prepared at the same crystallization temperature, which is consistent with the result that the uniformity of the thickness of crystals on RGO is better than that on CNT.

$\mathrm{PE} 21 \mathrm{Br} /$ nanofiller composites produced at $60^{\circ} \mathrm{C}$ and $15 \mathrm{MPa}$ $\mathrm{SC} \mathrm{CO}_{2}$ pressure were taken as examples for investigating the influence of $\mathrm{SC} \mathrm{CO}_{2}$ on the melting behavior of PE21Br crystals. Fig. 6 shows the melting behaviors measured by Flash DSC. The melting temperatures are given in Table 6. The melting peak temperature of $\mathrm{PE} 21 \mathrm{Br} / \mathrm{SWCNT}$ nancomposites produced at
Table 6 Melting data of $\mathrm{PE} 21 \mathrm{Br}$ and $\mathrm{PE} 21 \mathrm{Br} /$ nanofiller composites produced at $15 \mathrm{MPa} \mathrm{SC} \mathrm{CO}_{2}$ pressure

\begin{tabular}{lccl}
\hline Sample & $\begin{array}{l}T_{\mathrm{m}}\left({ }^{\circ} \mathrm{C}\right) \\
\text { peak }\end{array}$ & $\begin{array}{l}T_{\mathrm{m}}\left({ }^{\circ} \mathrm{C}\right) \\
\text { onset }\end{array}$ & $\begin{array}{l}\text { Onset-end } \\
\left({ }^{\circ} \mathrm{C}\right)\end{array}$ \\
\hline PE21Br & 77.6 & 62.3 & 24.8 \\
PE21Br/SWCNT & 96.9 & 61.8 & 60.2 \\
PE21Br/RGO & 144.1 & 112.1 & 53.8 \\
\hline
\end{tabular}

$60{ }^{\circ} \mathrm{C}$ is $96.9^{\circ} \mathrm{C}$ for $15 \mathrm{MPa}$, which is almost consistent with that prepared by traditional solution crystallization $\left(96.8{ }^{\circ} \mathrm{C}\right.$ in Table 5). The same result is also observed in $\mathrm{PE} 21 \mathrm{Br} / \mathrm{RGO}$ nanocomposites. This effect further confirms that the determinant of crystal lamellae thickness is the crystallization temperature, which is also in agreement with the analysis of TEM images (Tables 3 and 4). The melting ranges of PE21Br/ SWCNT and PE21Br/RGO nanocomposites prepared at $60{ }^{\circ} \mathrm{C}$ and $15 \mathrm{MPa} \mathrm{SC} \mathrm{CO}_{2}$ pressure are 60.2 and $53.8^{\circ} \mathrm{C}$, respectively, which are larger than those of the nanocomposites prepared by traditional solution crystallization $\left(18.7\right.$ and $28.9{ }^{\circ} \mathrm{C}$, as shown in Table 5). This also suggests that more lamellae with inhomogeneous thickness were formed under $\mathrm{SC} \mathrm{CO}_{2}$ because of the large amount and speed of the PE21Br precipitation. Similar to that produced by traditional solution crystallization, the melting range of $\mathrm{PE} 21 \mathrm{Br} / \mathrm{RGO}$ nanocomposites is smaller than that of $\mathrm{PE} 21 \mathrm{Br} / \mathrm{SWCNT}$ nanocomposites at $\mathrm{SC} \mathrm{CO}_{2}$.

\subsection{Crystalline structure of the PE21Br/nanofiller composites}

X-ray diffraction (XRD) was conducted to investigate the crystal structure of PE21Br/nanofiller composites. As shown in Fig. 7a and Table 7 , two peaks centered at $19.1^{\circ}$ and $20.8^{\circ}$ in the XRD pattern of PE21Br can be indexed as (100) and (010) diffractions of the triclinic form, respectively; ${ }^{50}$ however, the two diffractions become quite poor or even disappear. Instead, two new peaks that appear at $21.7^{\circ}$ and $23.1^{\circ}$ in PE21Br/SWCNT nanocomposites could be assigned to (110) and (200) diffractions of the orthorhombic form, respectively (Table 7). The orthorhombic
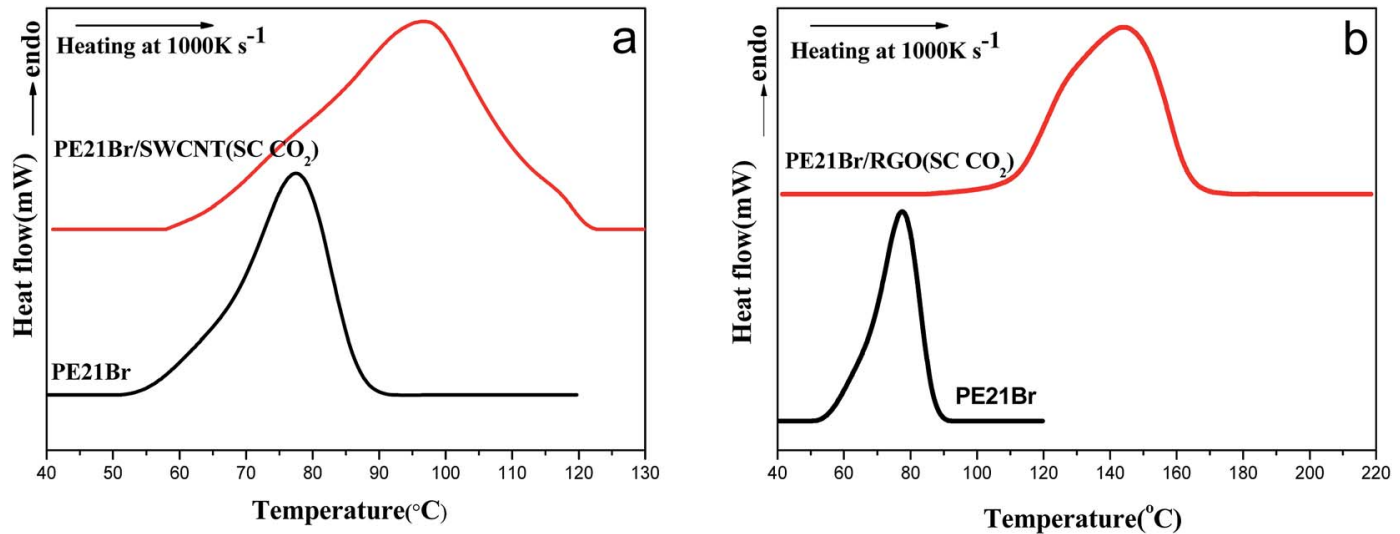

Fig. 6 First heating curves of $\mathrm{PE} 21 \mathrm{Br}$ and $\mathrm{PE} 21 \mathrm{Br} /$ nanofiller composites produced at $70{ }^{\circ} \mathrm{C}$ and different $\mathrm{SC} \mathrm{CO}_{2}$ pressures, as observed in the Flash DSC measurement at the constant heating rate of $1000 \mathrm{~K} \mathrm{~s}^{-1}$. (a) PE21Br/SWCNT nanocomposite and (b) PE21Br/RGO nanocomposite. 

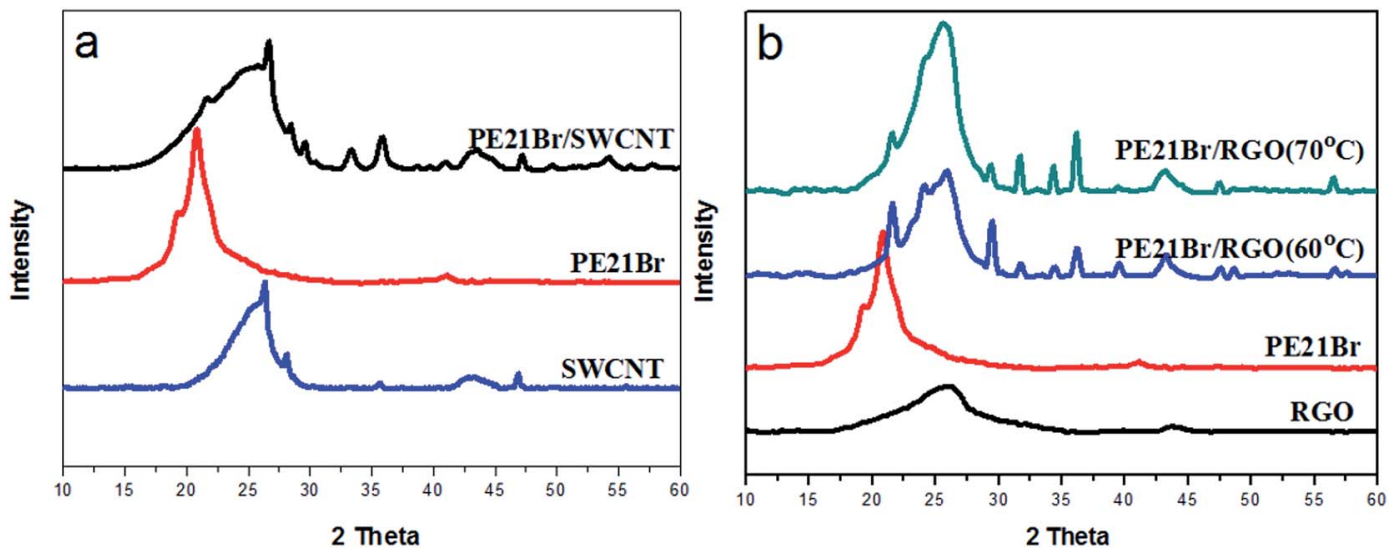

Fig. 7 XRD diffractograms of PE21Br, nanofillers, and PE21Br/nanofiller composites. (a) PE21Br/SWCNT nanocomposites and (b) PE21Br/RGO nanocomposites.

form structure can also be confirmed according to the higher $2 \theta$ peaks $29.9^{\circ}, 35.9^{\circ}$, and $39.9^{\circ}$, which can be indexed as (210), (020), and (011) diffractions of the orthorhombic form, respectively. The other peaks can be assigned to the contribution of SWCNT. From the abovementioned XRD results, we can draw a conclusion that SWCNT induced PE21Br to form an ordered lattice structure although $\mathrm{PE} 21 \mathrm{Br}$ has a larger volume of the substituent. The orthorhombic lattice parameters of the $\mathrm{PE} 21 \mathrm{Br} / \mathrm{SWCNT}$ nanocomposite were calculated to be $a=7.501$, $b=4.974$, and $c=2.548 \AA$, which fall between those of PE21F $(a=7.515, b=4.989 \text {, and } c=2.547 \AA)^{39}$ and $\operatorname{HDPE}(a=7.410, b=$ 4.934 , and $c=2.547 \AA$ ). Likewise, XRD results of the $\mathrm{PE} 21 \mathrm{Br} / \mathrm{RGO}$ nanocomposites are shown in Fig. 7b. A series of diffraction peaks of orthorhombic form centered at $21.6^{\circ}, 24.0^{\circ}, 29.5^{\circ}, 36.3^{\circ}$, and $39.5^{\circ}$ were again observed from $\mathrm{PE21Br} / \mathrm{RGO}$ nanocomposites prepared at $60{ }^{\circ} \mathrm{C}$ (Table 7). The other peaks can again be assigned to the contribution of RGO. On increasing the crystallization temperature of the PE21Br/RGO nanocomposites to $70{ }^{\circ} \mathrm{C}$ (Fig. $7 \mathrm{~b}$ ), two peaks at $21.6^{\circ}$ and $24.0^{\circ}$ assigned to (110) and (200) reflections of orthorhombic form become weak, which can be attributed to the fact that the quantity of epitaxial crystallized lamellae is small, especially at lower undercooling degree. The XRD results of the PE21Br/RGO nanocomposites indicate that the crystal structure of PE21Br epitaxially crystallized on the surface of RGO was transformed into the orthorhombic form from the triclinic form. This also supports the conclusion drawn from the analysis of the SAED pattern (Fig. 2d). The orthorhombic lattice parameters of PE21Br/RGO nanocomposites, calculated to be $a=7.416, b=4.945$, and $c=2.549$
$\AA$, also fall between those of $\mathrm{PE}^{2} 1 \mathrm{~F}^{39}$ and HDPE. The lattice parameters of PE21Br/RGO nanocomposites are larger than those of the PE21Cl/RGO nanocomposite $(a=7.314, b=4.920$, and $c=2.541 \AA)^{40}$ although both PE21Br and PE21Cl were induced by RGO to form orthorhombic structures. This indicates that the crystal structure of the $\mathrm{PE} 21 \mathrm{Br} / \mathrm{RGO}$ nanocomposite is less ordered than that of the $\mathrm{PE} 21 \mathrm{Cl} / \mathrm{RGO}$ nanocomposite because of the disturbance of the bulkier Br substituent. We can also find that the lattice parameters of $\mathrm{PE} 21 \mathrm{Br} / \mathrm{RGO}$ nanocomposites are lower than those of $\mathrm{PE} 21 \mathrm{Br} / \mathrm{SWCNT}$ nanocomposites, further indicating the different orderness of two crystals. X-ray diffractograms of $\mathrm{PE} 21 \mathrm{Br} /$ nanofiller composites

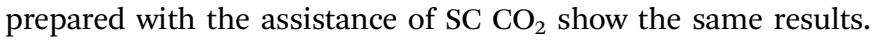
This effect indicates that although it can effectively promote the lateral growth of lamellae on CNT and RGO, $\mathrm{SC} \mathrm{CO}_{2}$ cannot change the crystal structure of the PE21Br/nanofiller composites.

Obviously, although the bromine substituent can be incorporated into the crystalline lattice of the PE backbone, ${ }^{50,51}$ it reduces the orderness of the continuous methylene sequences. Eventually, triclinic crystals are formed to facilitate the minimum spatial requirements to accommodate the bulky $\mathrm{Br}$ groups between adjacent molecules in the crystal, ${ }^{50,51}$ which also results in the much lower melting temperature of PE21Br compared to that of PE and PE21F with orthorhombic form. However, RGO and CNT transformed the triclinic form of PE21Br into the orthorhombic form according to the abovementioned results. The same crystal structure with different orderness may be attributed to different mechanisms of crystal formation on the SWCNT and RGO. For RGO, lattice matching

Table 7 XRD reflections for $\mathrm{PE} 21 \mathrm{Br}$ and $\mathrm{PE} 21 \mathrm{Br} /$ nanofiller composites

\begin{tabular}{|c|c|c|c|c|c|c|c|c|}
\hline \multirow[b]{2}{*}{ Sample } & \multirow[b]{2}{*}{ Packing cell } & \multicolumn{7}{|c|}{$2 \theta(\mathrm{deg})$} \\
\hline & & 010 & 100 & 110 & 200 & 210 & 020 & 011 \\
\hline $\mathrm{PE21Br/SWCNT}$ & Orthorh & & & 21.5 & 24.1 & 29.6 & 36.1 & 39.6 \\
\hline $\mathrm{PE} 21 \mathrm{Br} / \mathrm{RGO}\left(60^{\circ} \mathrm{C}\right)$ & Orthorh & & & 21.6 & 24.0 & 29.5 & 36.3 & 39.5 \\
\hline $\mathrm{PE} 21 \mathrm{Br} / \mathrm{RGO}\left(70^{\circ} \mathrm{C}\right)$ & Orthorh & & & 21.6 & 24.0 & 29.5 & 36.3 & 39.5 \\
\hline
\end{tabular}


should play the dominant role in polymer epitaxial crystallization. On the basis of structural analysis of epitaxial crystallization, the chain direction $\langle 001\rangle$ and the $\{110\}$ plane of the orthorhombic $\mathrm{PE} 21 \mathrm{Br}$ are parallel to the $\langle 2-1-10\rangle$ direction and the (0001) plane of RGO, respectively. ${ }^{17,32}$ However, only the chain axis of $\mathrm{PE} 21 \mathrm{Br},\langle 010\rangle$, may be indexed as parallel to the $\langle 2-1-10\rangle$ RGO. ${ }^{17,32}$ Using the lattice parameters of PE21Br and RGO, we calculated the lattice mismatch value along the chain axis of $\mathrm{PE} 21 \mathrm{Br}$ to be $3.6 \%$ for the orthorhombic form, while the lattice mismatch along the direction perpendicular to the chain axis is $3.8 \% .^{31,32}$ The periodic length of the PE21Br triclinic form along the chain axis was 4.15-5.27 $\mathrm{nm}$ (ref. 52) and then the lattice mismatch value was much larger than $15 \%$. Therefore, PE21Br has epitaxial crystallization on RGO only with the orthorhombic form. One-dimensional CNT can also induce the transformation of the crystal from the triclinic form of $\mathrm{PE} 21 \mathrm{Br}$ to the orthorhombic form, but the lattice parameter of the PE21Br lamellae formed on SWCNT is slightly larger than that formed on RGO because of the absence of strict lattice matching. Therefore, different mechanisms of SWCNT and RGO result in different capacities, where both nanofillers induce substituted polymers to crystallize and generate the ordered chain packing structure. The experimental results are in good agreement with those obtained by computer simulation. ${ }^{37,38}$ Ordered lattice structure caused by epitaxial crystallization causes the melting temperature of polymers to notably increase, which allows models for fabricating functional polyolefin materials with high service temperature and provides guidance to prepare polymer-carbonaceous nanocomposites with expected physical properties as well as other functionalities.

\section{Conclusion}

The epitaxial crystallization behavior of PE21Br on two different types of structural nanofillers was investigated. SWCNT and RGO induced the structural transformation of PE21Br from the triclinic form to the orthorhombic form, which generated extraordinarily high melting temperatures. The different orthorhombic lattice parameters and melting temperatures of $\mathrm{PE} 21 \mathrm{Br} / \mathrm{SWCNT}$ and PE21Br/RGO nanocomposites are ascribed to different mechanisms of PE21Br crystallization on SWCNT and RGO. SC $\mathrm{CO}_{2}$ can accelerate the lateral growth of lamellae and form lamellae with inhomogeneous thickness on nanofillers. This finding has attracted our interest in further investigating the epitaxial crystallization behavior of other precision systems with bulkier substituents and higher content of substituents.

\section{Acknowledgements}

This work is financially supported by the National Natural Science Foundation of China (No. U1532114 and 51403110), Natural Science Foundation of Zhejiang Province (LY15B040003), Natural Science Foundation of Ningbo Municipal (2015A610021), and K. C. Wong Magna Fund in Ningbo University.

\section{References}

1 S. Cheng, W. Hu, Y. Maand and S. Yan, Polymer, 2007, 48, 4264-4270.

2 B. Na, K. Wang, P. Zhao, Q. Zhang, R. Du, Q. Fu, Z. Yu and E. Chen, Polymer, 2005, 46, 5258-5267.

3 Y. J. Park, S. J. Kang, B. Lotz, M. Brinkmann, A. Thierry, K. J. Kim and C. Park, Macromolecules, 2008, 41, 8648-8654.

4 H. Chang, J. Zhang, L. Li, Z. Wang, C. Yang, I. Takahashi, Y. Ozaki and S. Yan, Macromolecules, 2009, 43, 362-366.

5 J. Yang, C. Wang, K. Wang, Q. Zhang, F. Chen, R. Du and Q. Fu, Macromolecules, 2009, 42, 7016-7023.

6 R. Su, K. Wang, Q. Zhang, F. Chen, Q. Fu, W. Xu and B. Na, J. Phys. Chem. B, 2009, 113, 7423-7429.

7 J. Zhang, Y. Duan, S. Yan, C. Yang, I. Takahashi and Y. Ozaki, Macromolecules, 2010, 43, 5315-5322.

8 J. C. Wittmann and B. Lotz, Prog. Polym. Sci., 1990, 15, 909-948. 9 S. Yan, F. Katzenberg, J. Petermann, D. Yang, Y. Shen, C. Straupe, J. C. Wittmann and B. Lotz, Polymer, 2000, 41, 2613-2625.

10 A. Thess, R. Lee, P. Nikolaev, H. J. Dai, P. Petit and J. Robert, Science, 1996, 273, 483-487.

11 S. J. Tans, M. H. Devoret, H. J. Dai, A. Thess, R. E. Smalley and L. J. Geerligs, Nature, 1997, 386, 474-477.

12 M. J. Allen, V. C. Tung and R. B. Kaner, Chem. Rev., 2010, 110, 132-145.

13 H. Kim, A. A. Abdala and C. W. Macosko, Macromolecules, 2010, 43, 6515-6530.

14 X. Zheng and Q. Xu, J. Phys. Chem. B, 2010, 114, 9435-9444. 15 M. S. P. Shaffer and A. H. Windle, Adv. Mater., 1999, 11, 937941.

16 J. Z. Xu, T. Chen, C. L. Yang, Z. M. Li, Y. M. Mao, B. Q. Zeng and B. S. Hsiao, Macromolecules, 2010, 43, 5000-5008.

17 S. Cheng, X. Chen, Y. G. Hsuan and C. Y. Li, Macromolecules, 2012, 45, 993-1000.

18 J. Yue, Q. Xu, Z. Zhang and Z. Chen, Macromolecules, 2007, 40, 8821-8826.

19 X. Zheng, Q. Xu, L. He, N. Yu, S. Wang, Z. Chen and J. Fu, J. Phys. Chem. B, 2011, 115, 5815-5826.

20 F. Zhang, H. Zhang, Z. Zhang, Z. Chen and Q. Xu, Macromolecules, 2008, 41, 4519-4523.

21 S. Manna and A. K. Nandi, J. Phys. Chem. C, 2007, 111, 14670-14680.

22 J. Z. Xu, G. J. Zhong, B. S. Hsiao, Q. Fu and Z. M. Li, Prog. Polym. Sci., 2014, 39, 555-593.

23 S. Yang, D. Meng, J. Sun, W. Hou, Y. Ding, S. Jiang, Y. Huang and J. Geng, RSC Adv., 2014, 4, 25051-25056.

24 W. Zhu, O. Yang, J. Sun, J. Memon, C. Wang, J. Geng and Y. Huang, Carbon, 2013, 62, 501-509.

25 F. Mai, K. Wang, M. Yao, H. Deng, F. Chen and Q. Fu, J. Phys. Chem. B, 2010, 114, 10693-10702.

26 H. Deng, T. Skipa, R. Zhang, D. Lellinger, E. Bilotti, I. Alig and T. Peijs, Polymer, 2009, 50, 3747-3754.

27 H. Deng, T. Skipa, E. Bilotti, R. Zhang, D. Lellinger, L. Mezzo, Q. Fu, I. Alig and T. Peijs, Adv. Funct. Mater., 2010, 20, 14241432. 
28 S. L. Kodjie, L. Li, B. Li, W. Cai, C. Y. Li and M. Keating, J. Macromol. Sci., Part B: Phys., 2006, 45, 231-245.

29 C. Y. Li, L. Li, W. Cai, S. L. Kodjie and K. K. Tenneti, Adv. Mater., 2005, 17, 1198-1202.

30 L. Li, C. Y. Li and C. Ni, J. Am. Chem. Soc., 2006, 128, 16921699.

31 F. Tuinstra and E. Baer, J. Polym. Sci., Part B: Polym. Phys., 1970, 8, 861-865.

32 Y. Takenaka, H. Miyaji, A. Hoshino, A. Tracz, J. K. Jeszka and I. Kucinska, Macromolecules, 2004, 37, 9667-9669.

33 X. Hu, H. An, Z. M. Li, Y. Geng, L. Li and C. Yang, Macromolecules, 2009, 42, 3215-3218.

34 A. Tracz, J. K. Jeszka, I. Kucinska, J. P. Chapel, G. Boiteux and M. Kryszewski, J. Appl. Polym. Sci., 2002, 86, 1329-1336.

35 A. Tracz, I. Kucinska and J. K. Jeszka, Macromolecules, 2003, 36, 10130-10132.

36 A. Tracz, I. Kucinska and J. K. Jeszka, Polymer, 2006, 47, 7251-7258.

37 Y. Li, M. Kroger and W. K. Liu, Macromolecules, 2012, 45, 2099-2112.

38 Y. Li, Polymer, 2011, 52, 2310-2318.

39 W. Miao, Y. Lv, W. Zheng, Z. Wang and Z. R. Chen, Polymer, 2016, 83, 205-213.

40 W. Miao, Z. Wang, Z. Li, W. Zheng and Z. R. Chen, Polymer, 2016, 94, 53-61.
41 E. Boz, A. J. Nemeth, R. G. Alamo and K. B. Wagener, Adv. Synth. Catal., 2007, 349, 137-141.

42 B. Wang, H. Li, Z. Li, P. Chen, Z. Wang and Q. Gu, Compos. Sci. Technol., 2013, 89, 180-185.

43 Z. Zhang, Q. Xu, Z. Chen and Z. Yue, Macromolecules, 2008, 41, 2868-2873.

44 F. Zhang, Q. Xu, H. Zhang and Z. Zhang, J. Phys. Chem. C, 2009, 113, 18531-18535.

45 N. Yu, X. Zheng, Q. Xu and L. He, Macromolecules, 2011, 44, 3958-3965.

46 N. Yu, L. He, Y. Ren and Q. Xu, Polymer, 2011, 52, 472-480.

47 A. Toda, K. Taguchi, K. Nozaki and M. Konishi, Polymer, 2014, 55, 3186-3194.

48 H. Gao, J. Wang, C. Schick, A. Toda, D. Zhou and W. Hu, Polymer, 2014, 55, 4307-4312.

49 Z. Li, X. Jiang, H. Gao, D. Zhou and W. Hu, J. Therm. Anal. Calorim., 2014, 118, 1531-1536.

50 R. G. Alamo, K. Jeon, R. L. Smith, E. Boz, K. B. Wagener and M. R. Bockstaller, Macromolecules, 2008, 41, 7141-7151.

51 E. Boz, K. B. Wagener, A. Ghosal, R. Fu and R. G. Alamo, Macromolecules, 2006, 39, 4437-4447.

52 M. Tasaki, H. Yamamoto, M. Hanesaka, K. Tashiro, E. Boz, K. B. Wagener, C. Ruiz-Orta and R. G. Alamo, Macromolecules, 2014, 47, 4738-4749. 